\title{
STUDY OF THE NANOMETRIC GRAIN SIZE DISTRIBUTION IN IRON COMPACTS OBTAINED BY MECHANICAL MILLING
}

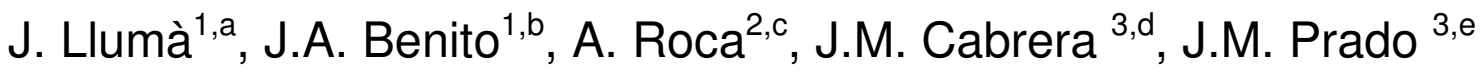 \\ ${ }^{1}$ Departamento de Ciencia de Materiales e Ingeniería Metalúrgica, EUETIB, Universidad \\ Politécnica de Cataluña (UPC), c/ Urgell, 187, 08036-Barcelona, Spain. \\ ${ }^{2}$ Departamento de Ingeniería Química y Metalurgia, Facultad de Química, Universidad de \\ Barcelona (UB), c/ Martí i Franquès, 1, 08028-Barcelona, Spain. \\ ${ }^{3}$ Departamento de Ciencia de Materiales e Ingeniería Metalúrgica, ETSEIB, Universidad \\ Politécnica de Cataluña (UPC), Av. Diagonal, 647, 08028-Barcelona, Spain. \\ a jordi.lluma@upc.edu, ${ }^{b}$ josep.a.benito@upc.edu, ${ }^{c}$ roca@material.qui.ub.es, \\ jose.maria.cabrera@upc.edu, ${ }^{\mathrm{e}} \mathrm{jm}$. prado@upc.edu
}

Keywords: mechanical milling, iron powder, grain size distribution

\begin{abstract}
A study has been carried out on the grain size distribution of cylindrical compacts obtained by consolidation of iron powder severely deformed by mechanical milling. Consolidation has been performed in two consecutive steps: cold and hot conditions. The hot one was done at two temperatures, namely 425 and $475^{\circ} \mathrm{C}$. After milling, the iron powder has a grain size of $8 \mathrm{~nm}( \pm 4$ $\mathrm{nm}$ ) with an average hardness of $800 \mathrm{HV}$. After hot compaction the grain size increases up to 50 $\mathrm{nm}$, especially at $475^{\circ} \mathrm{C}$ where a small fraction of grains reach larger values than the average. The grain size was evaluated by two different techniques, X-Ray Diffraction and Transmission Electron Microscopy. Results showed some differences between both methods. The advantage of using TEM is that grain size distribution, and not only the average size, can be obtained. Small discs were also obtained from the compacted specimen in order to fracture them on a "ball on three balls" equipment. The fracture behaviour of the samples was then studied by SEM.
\end{abstract}

\section{Introduction}

Metallic materials with nanometric grain size are being actively studied due to the potential mechanical characteristics they could offer. It has been reported [1-3] that mechanical resistance or hardness values be can increased by a factor five regarding the same materials with micrometric grain size. However, other properties, such as ductility or toughness are offering relatively poorer results than conventional (micrometric) materials [4] leading to limited applications of this new materials.

The lack of ductility under tensile tests has been associated to non-homogeneous deformation, i.e., deformation bands, at the onset of plastic deformation. These local deformations promotes early fractures with elongations as low as 3\% without strain hardening [4]. Some authors [5] have pointed out that this behaviour is related to the grain size distribution, and more specifically to the role played by a few larger grains (still in the nanometric scale) present in the grain size distribution. It has been proposed that they define privileged deformation orientations [5].

Iron is one of the most studied metals to get nanometric grain sizes. Two principal routes are employed: mechanical milling and equal channel angular pressing, both involving severe plastic deformation $[1,2,5,7,9]$. In the mechanical milling route, the challenge of the process is to obtain $100 \%$ compact samples keeping the grain size at the same level that the one obtained in the milling. The process is usually carried out in two steps. First, a cold compaction under large pressure, and 
second a hot compaction at temperatures ranging $400^{\circ}$ to $600^{\circ} \mathrm{C}$ during holding periods from $30 \mathrm{~min}$ until 5 hours $[1,5,6,7]$. In this second step some grain growth can occur, although the nanometric (or submicrometric) scale is maintained (depending on temperature and time). The main problem of this step is the possible apparition on abnormal grain growth which leads to obtain a few large grain sizes. The grain size of these type of materials is usually obtained by X-ray diffraction techniques. This method gives the average grain size but no information is provided about the grain size distribution. Ma et al [5] have observed the presence of a small number of grains with clearly larger sizes than the average. Bearing in mind the above paragraphs, the main goal of the present work is to study the distribution of grain sizes in iron processed by mechanical milling.

\section{Experimental procedure}

Iron powder of high purity, with irregular morphology and initial particle size ranging 75 to $160 \mu \mathrm{m}$, was severely deformed in a planetary ball milling for 60 hours rotating at $160 \mathrm{rpm}$. Stainless steel recipients and Cr-steel balls were used for this purpose. The ratio balls - powder was 27:1. Additionally a small amount (0.8\% weight) of EBS (Etilen-bis-stearamide) was added to avoid the adherence of the powder to the walls of the recipient. A light Ar pressure was introduced in the recipients to prevent oxidation. Finally, stand-by periods were introduced in the milling cycles to minimize the increment of temperature inside the recipient [10]. The powder obtained (see figure 1) was refined up to $6 \mu \mathrm{m}$ in diameter, as shown in the distribution function (figure 2) obtained by a laser particle analyzer. The iron powder had an average hardness of $800 \mathrm{HV}$ determined with a microhardness tester with loads of $0,098 \mathrm{~N}$.

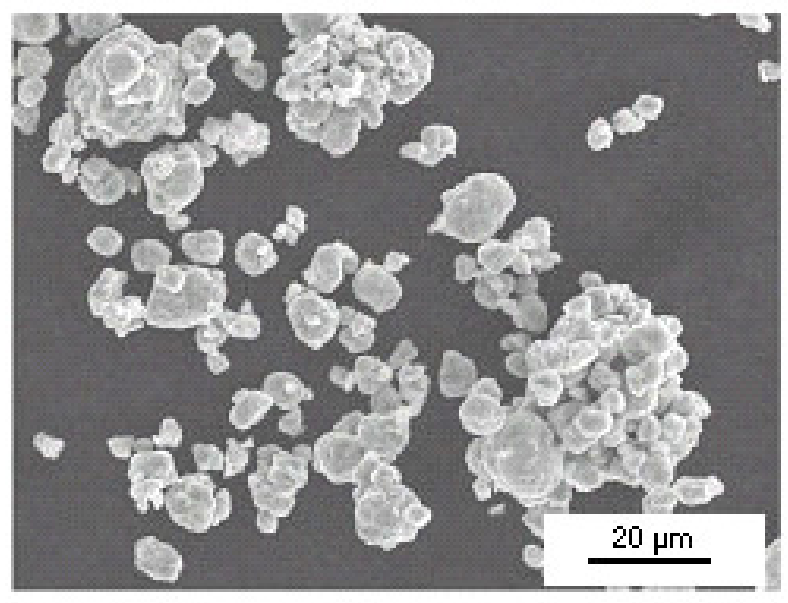

Figure 1. Aspect of the iron powder after 60 hours of milling.

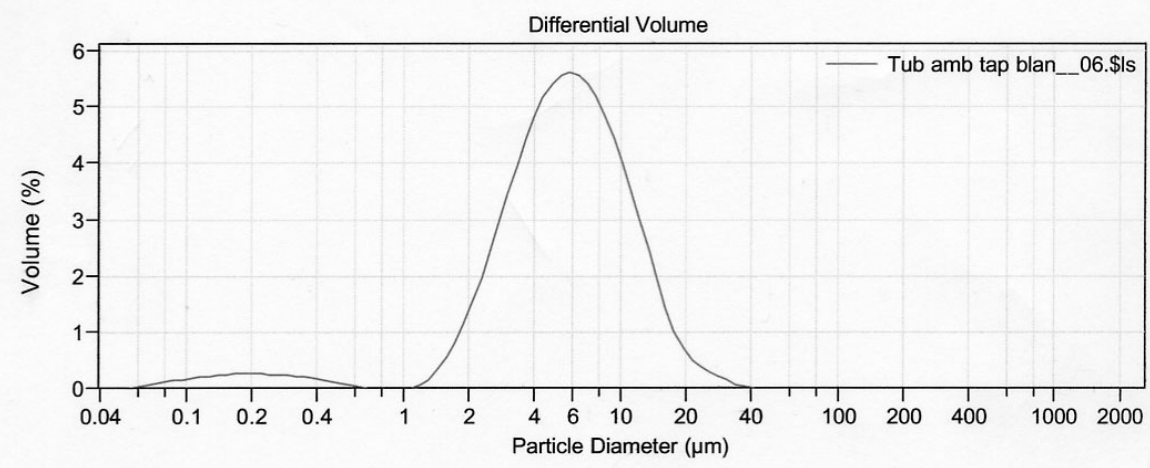

Figure 2. Size distribution of the iron powder at the end of the milling step.

The grain size in powder or compact state was evaluated by X-Ray Diffraction and Transmission Electron Microscopy (TEM). In the case of X-Ray Diffraction CuKa radiation with wavelength 
$\lambda=0,1540 \mathrm{~nm}$ was employed in a Siemens equipment. The grain size was then calculated by the Scherrer's formula [11] measuring the width, at medium height, of peaks corresponding to planes $\{110\},\{200\},\{211\}$ and $\{220\}$. Alternatively, the Hall-Williamson [12] method was also employed to derive the grain size. However results were inconsistents and therefore the method was discarded.

TEM analyses were carried out in a Phillips CM30 operating at $300 \mathrm{kV}$. The grain size was then measured by image analysis from both bright and dark field images. Selected are diffraction (SAD) were obtained in all cases.

Powder compaction was done on an INSTRON 8501 testing machine. For this purpose a cylindrical mould of $9.2 \mathrm{~mm}$ of inner diameter was machined in a maraging steel. $2.5 \mathrm{~g}$ of milled iron powder were introduced in the mould. Then $1100 \mathrm{MPa}$ were applied for 5 minutes and a cylinder of $5 \mathrm{~mm}$ in height was obtained. Following, the hot compaction step applied $450 \mathrm{MPa}$ for 45 minutes at two temperatures, $425^{\circ} \mathrm{C}$ and $475^{\circ} \mathrm{C}$, in order to obtain different grain size distributions.

The porosity was evaluated by measuring the dimensions and weight of the samples, using a theoretical density for iron of $7.87 \mathrm{gr} / \mathrm{cm}^{3}$. Hardness of consolidated specimens was evaluated by Vickers indentations applying a load of $1,96 \mathrm{~N}$. Values were averaged on 40 measurements through the longitudinal section of the sample. To study the effect of the porosity and compaction degree, small discs ( $1 \mathrm{~mm}$ thick) were machined from the transversal section of the consolidated specimen. They were then tested by a "ball on three balls" system [13,14]. The fracture surface of the specimens were then analysed by Optical and Scanning Electron Microscopy.

\section{Results and discussion.}

Analysis of grain structure in consolidated samples. The characteristics of samples obtained after consolidation are listed in table 1. It can be noticed that the grain size increases with regard to the size obtained by mechanical milling, although the nanometric size is still maintained. This larger grain sizes correlate with the decreasing hardness observed. No significant differences were found regarding the hot compaction temperature. Remarkable different values of grain sizes were obtained depending of the technique used to evaluate them. In particular, the XRD technique seems to offer narrower errors. The relationship between hardness and grain size for the powder milled and for the powder once consolidated at $475^{\circ} \mathrm{C}$ are in accordance with similar results reported in the literature $[1,6,7]$. However, hardness values are slightly lower than expected, especially at $425^{\circ} \mathrm{C}$, probably due to the larger porosity.

\begin{tabular}{|c|c|c|c|c|}
\hline MATERIAL & \% Porosity & HV & $\begin{array}{c}\mathrm{d}_{\mathrm{o}} \text { XRD } \\
(\mathrm{nm})\end{array}$ & $\begin{array}{c}\mathrm{d}_{\mathrm{o}} \text { TEM } \\
(\mathrm{nm})\end{array}$ \\
\hline Powder (milled) & -- & $800 \pm 75$ & $8 \pm 4$ & -- \\
\hline Compact sintered at $425^{\circ} \mathrm{C}$ & 93 & $620 \pm 50$ & $37 \pm 15$ & $21 \pm 12$ \\
\hline Compact sintered at $475^{\circ} \mathrm{C}$ & 96 & $640 \pm 55$ & $45 \pm 16$ & $53 \pm 45$ \\
\hline
\end{tabular}

Table 1. Amount of porosity (\%), hardness $\left(\mathrm{HV}_{0,2}\right)$ and average grain size $\left(\mathrm{d}_{\mathrm{o}}\right)$ obtained by $\mathrm{X}$-Ray Diffraction (XRD) and by Transmission Electron Microscopy (TEM).

A bright-field image (BF) TEM image and its corresponding selected-area diffraction pattern of the grain structure in the simple compacted at $425^{\circ} \mathrm{C}$ are shown in figure $3 \mathrm{a}$. One can notice how difficult is to derive the grain size from this picture. The large amount of defects, the lack of clear grain boundaries and the superposition of grains (in the width direction) do not help in measuring the grain size. In contrast, the corresponding dark-field image shows in a clearer way some grains. From this dark-field picture and other similars, and by image analysis, the grain size distribution for 
this sample was derived. The distribution is relatively narrow as shown in figure 4 . The hot compaction has permitted the apparition of equiaxed grains eliminating the elongated grains obtained in the milling process [15]. This fact is confirmed by the regularity of the diffraction rings, as depicted in the SAD which appear free of dots in the interior of ring corresponding to planes $\{110\}$. This indicates the small presence of oxides or even cementite in the samples.

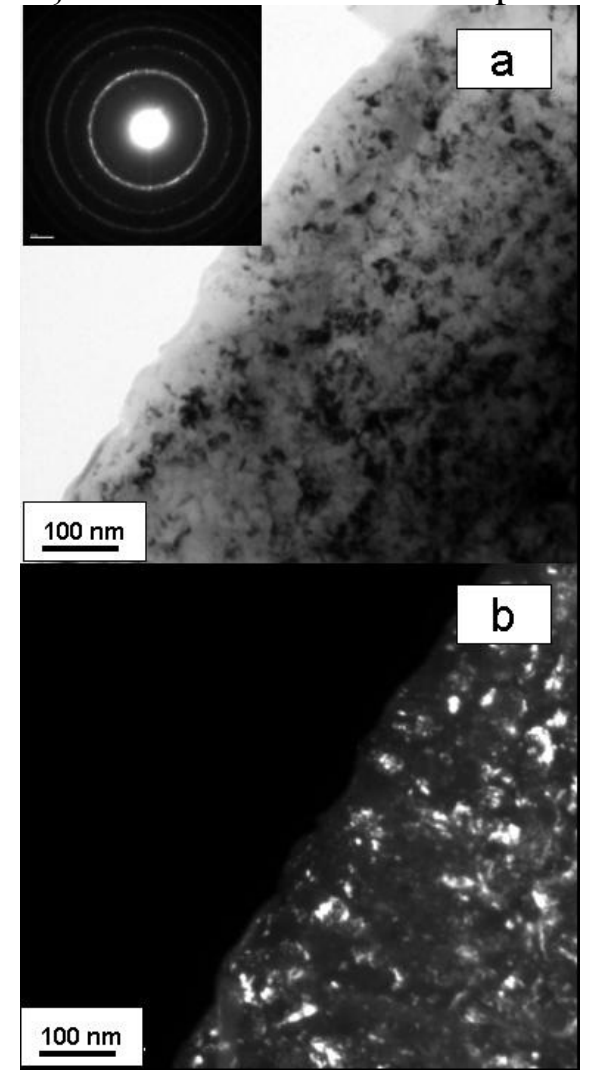

Figure 3. Bright-field and

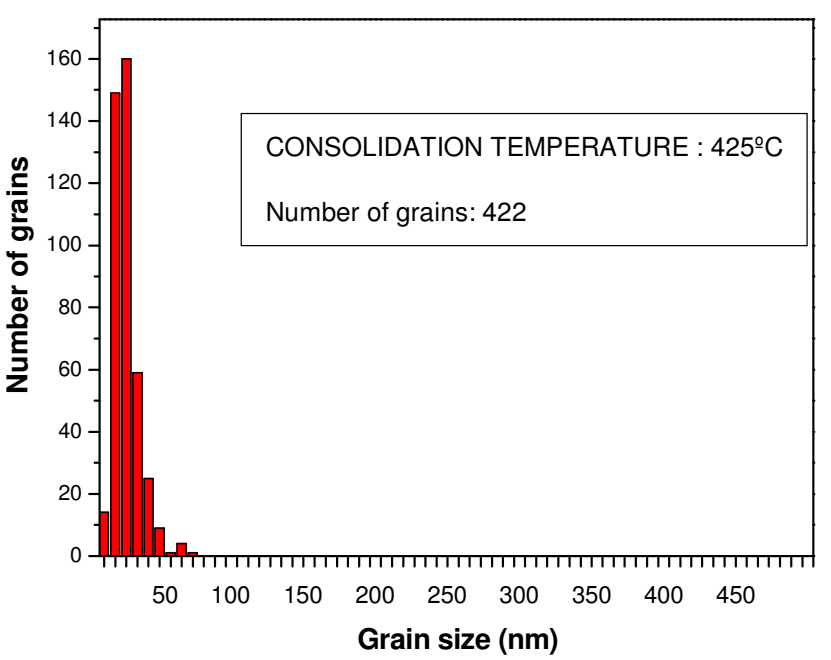

Figure 4. Grain size distribution in samples consolidated at $425^{\circ} \mathrm{C}$.

corresponding SAD (a) and dark field

(b) TEM images showing the grain

structure in samples consolidated at $425^{\circ} \mathrm{C}$.

A bright-field image (BF) TEM image and its corresponding SAD pattern of the grain structure in the sample consolidated at $475^{\circ} \mathrm{C}$ are shown in figure 5a. It is apparent now a larger equiaxed grain which at the same time facilitate its evaluation. Grain boundaries are now more evident. SAD images display several dots not corresponding to the iron diffraction rings, indicating that some contamination in the process or apparition of new phases can be occurring, both enhanced by the increment in temperature. The grain size distribution of samples compacted at $475^{\circ} \mathrm{C}$ is shown in figure 6. This distribution, centred at larger values than the corresponding at $425^{\circ} \mathrm{C}$, has a significant right-hand tail, with grains sizes 7 or more times larger than the average. This is clearly depicted in figure 7. It is evident that this difference in grain sizes should be promoting non-homogeneous deformation $[4,5]$.

Analysis of fracture in consolidated samples. The fracture surface of a sample consolidated at $425^{\circ} \mathrm{C}$ is shown in figure $8 \mathrm{a}$. A high decohesion between particles of the milled powder is observed. Fracture is mainly brittle. Fracture cracks grow through the initial particles, indicating that the amount of compaction is probably lower than the one evaluated. On the other hand, the fracture surface of the sample consolidated at $475^{\circ} \mathrm{C}$ displays a better aspect in the sense that less decohesion is observed, which must be linked with the lower porosity of this sample (see table 1). Fracture is also brittle but in certain areas the crack grows crossing particles. In this latter case, the fracture 
surface is inhomogeneous, having a mix of intra (figure 9a) and transgranular (figure $9 \mathrm{~b}$ and c). No evidence of plastic deformation has been found on the two samples. The shear bands reported by some authors have not been found either [5,7].

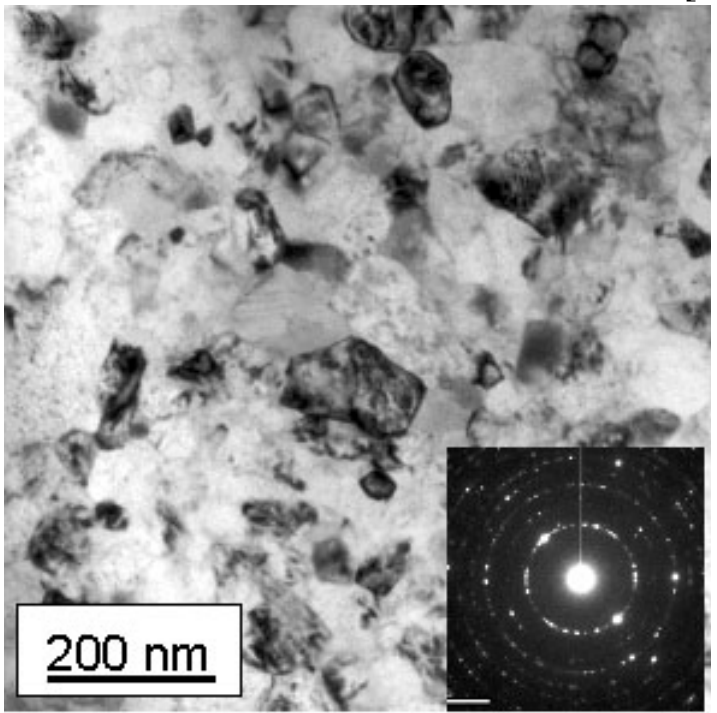

Figure 5. Bright-field TEM image and corresponding SAD showing grain structure of a sample consolidated at $475^{\circ} \mathrm{C}$.

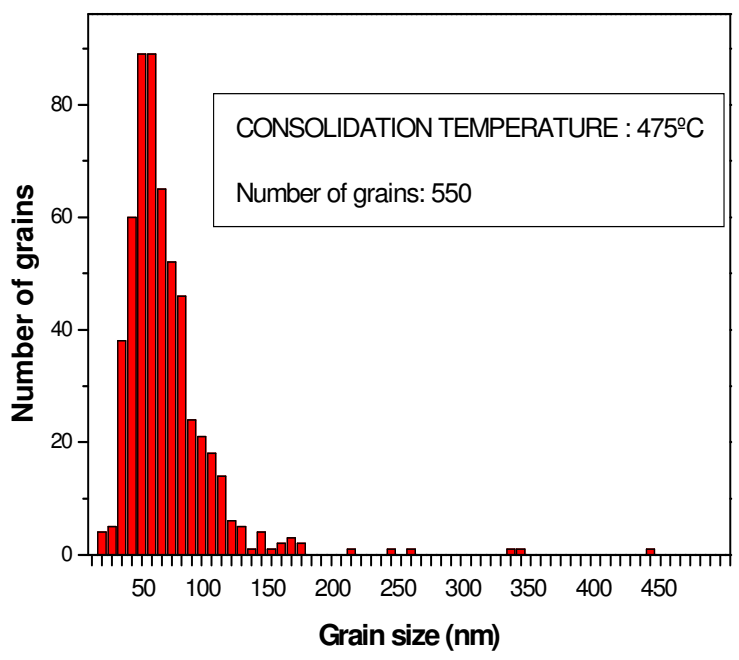

Figure 6. Grain size distribution in samples consolidated at $475^{\circ} \mathrm{C}$.

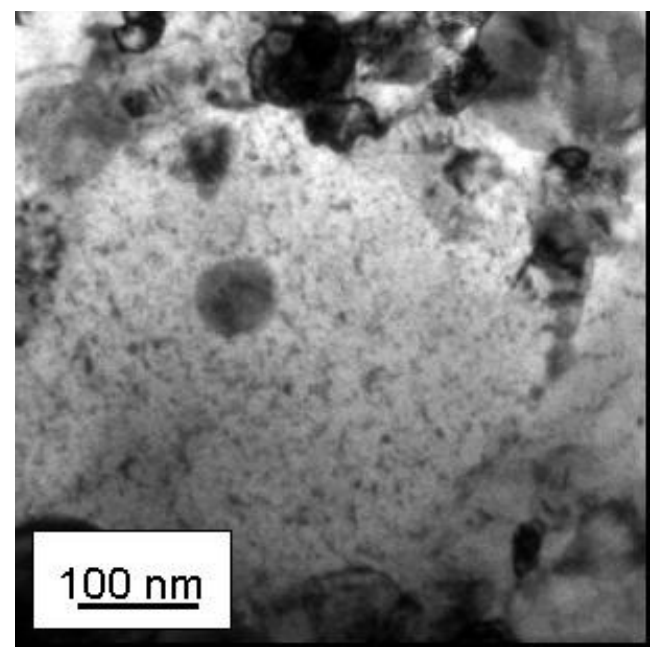

Figure 7. Bright-field image of a large grain of ferrite observed in a sample consolidated at $475^{\circ} \mathrm{C}$.
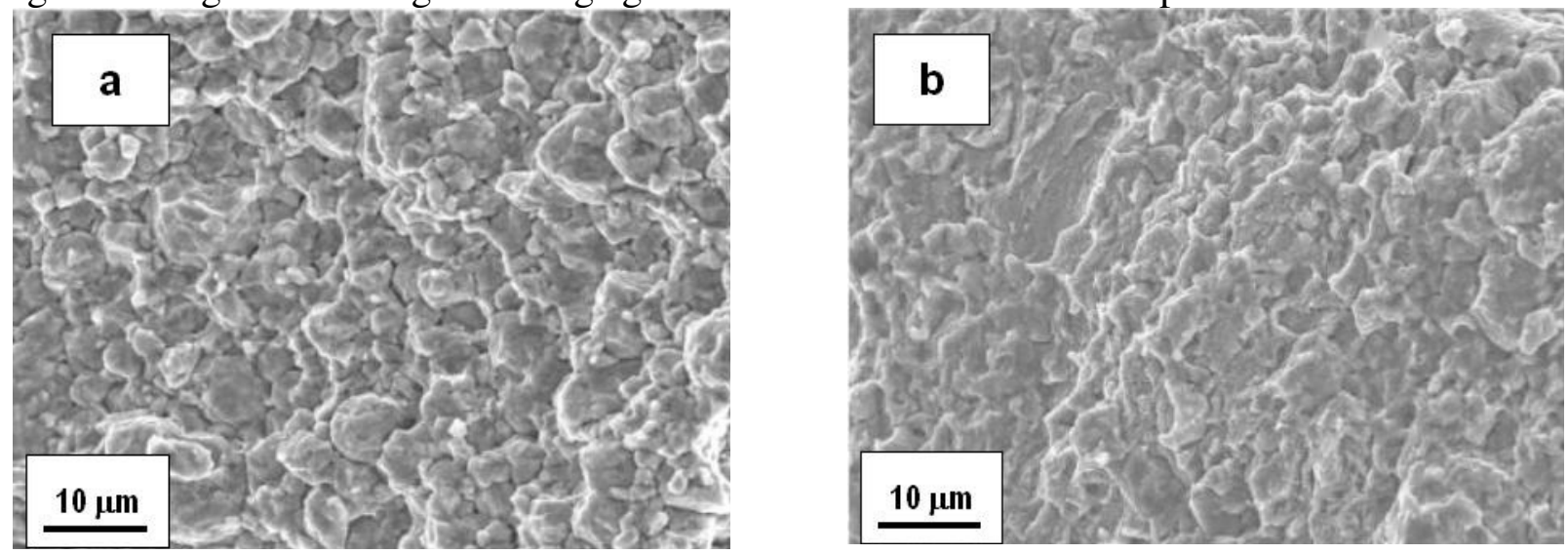

Figure 8. SEM images of the fracture surface after ball on three balls test on : a) samples consolidated at $425^{\circ} \mathrm{C}$, and b) samples consolidated at $475^{\circ} \mathrm{C}$. 


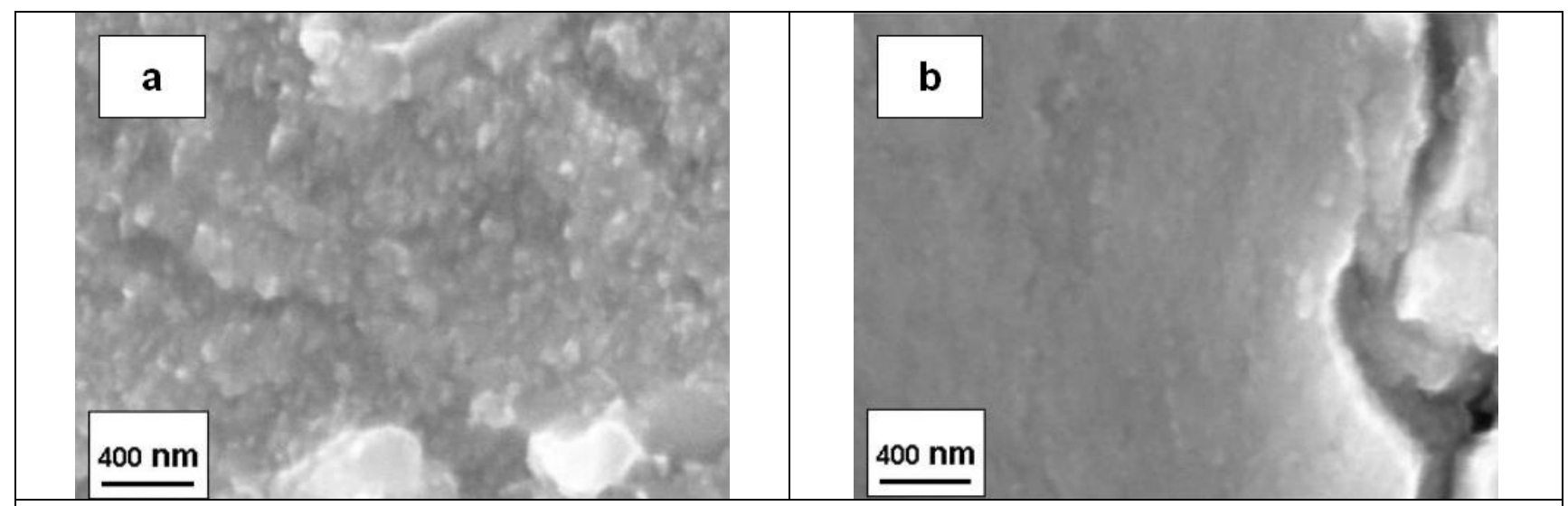

Figure 9. SEM images of fracture surface of samples consolidated at $475^{\circ} \mathrm{C}$. In these images the crack run through the initial milled particles. The fracture seems to be transgranular in a), but in b)

flat surfaces suggests that crack progresses also through the ferrite grains.

\section{Conclusions}

The grain structure of compacted materials after cold plus hot compression is equiaxed and free of oxide. Determination of grain size by TEM has been possible although some difficulties have arisen in samples sintered at $425^{\circ} \mathrm{C}$. No perfect agreement was obtained in the grain sizes measured by TEM or by XRD. These differences were minor in the case of sintering at $475^{\circ} \mathrm{C}$. A wider grain size distribution was apparent under the high temperature sintering conditions. Especially remarkable is the fact of very large grain sizes in this distribution. The fracture behaviour was clearly brittle, mainly due to intergranular fracture. Efforts should be addressed to reduce the porosity. No plastic deformation was noticed

\section{Acknowledgements}

Authors thanks Mr. Adrián Feder (Fatigue and fracture group of UPC) his facilities in the ball on three balls test. As well, the support offered by Pep Bassas (Serveis Científico Tècnics of UB) is kindly acknowledged. Financial support has been provided by CICYT (project DPI 2002-04479).

\section{References}

[1] J. Rawers and R. Krabbe: J. Mater. Synth. and Process. Vol. 6, 1998, p.133.

[2] T.R. Mallow and C.C. Koch: Acta Mater., Vol. 45, 1997, p. 2177.

[3] E. Ma: Powder. Metall., Vol. 43, 2000, p. 306.

[4] Y.M. Wang and E. Ma: Mater. Sci and Eng. A, Vol.375-377, 2004, p. 46.

[5] D. Jia, K.T. Ramesh and E. Ma: Acta Mater., Vol. 51, 2003, p. 3495.

[6] A. Khan, H. Zhang, H. Takacs: Int. Journal Plasticity, Vol.16, 2000, p. 1459.

[7] T.R. Mallow and C.C. Koch: Acta Mater., Vol.46, 1998, p. 6459.

[8] A. Borger, P. Supancic and R. Danzer : Journal Eur. Cer. Soc., Vol. 22, 2002, p. 1425.

[9] Y. Yin, M. Umemoto, K. Tsuchiya, ISIJ Int, Vol. 41, 2001, p. 1389.

[10] A. López, E. Arias, J. A Benito, A. Roca, J. M. Cabrera and J.M. Prado: VIII Congreso Nacional de Materiales, Servei Publicacions de la UPV, Valencia 2004, p. 359.

[11] A. Guinier: X-Ray diffraction, Ed. W. H. Freeman and Co, (1963), p. 121.

[12] G.K. Williamson and W.H. Hall: Acta Metall. Vol.1, 1953, p. 22.

[13] A. Villuendas, J. Llumà, J.A. Benito, A. Roca, J.M. Cabrera and J.M. Prado: Anales Mecánica de la Fractura, n $^{\text {2 } 22, ~ 2005, ~ p . ~} 514$.

[14] A. Borger, P. Supancic and R. Danzer, Journal Eur. Cer. Soc., Vol. 24, 2004, p. 2917.

[15] M. Murayama, J.M. Howe, H. Hidaka and S. Takaki: ISIJ Int., Vol. 43, 2003, p. 755. 